\title{
Improvement of industrialization projects management: An automotive industry case study
}

\author{
Diana Fernandes, Anabela Tereso and Gabriela Fernandes \\ Production and Systems Department / Centre ALGORITMI \\ University of Minho, Campus de Azurém, 4804-533 Guimarães, Portugal \\ pg31496ealunos.uminho.pt, \\ anabelat@dps.uminho.pt, g. fernandes@dps.uminho.pt
}

\begin{abstract}
.
Nowadays, in response to the technological evolution of the markets, organizations need to effectively improve their product development process. The product development can be seen as a global project where the industrialization project is a subproject of the product development project. The use of an integrated project management process helps to ensure projects completion according to the schedule plan and to keep the cost inside the budget and the quality with acceptable standards. The main objective of this research was the improvement of the project management practices in industrialization projects in a company of the automotive sector. An integrated project management process was developed and key project management tools and techniques were proposed, considering the project organizational context. The stakeholders who participated in this research study perceived that improvements proposed will be an added value to the company, however, due to the time constraints, it was not possible to test and quantify the real benefits of the proposed improvements on the management of industrialization projects.
\end{abstract}

Keywords: Project Management, Industrialization Projects, Integrated Process of Project Management, Automotive Industry.

\section{Introduction}

The constant search for new and better products leads to the creation of new processes of product development, these being crucial to pay special attention to the aspects of quality and safety of the final product. Due to the high competitiveness of the automotive industry, time to market must be reduced, therefore requiring tailored and standardized processes [1, 2]. Data from a survey carried out by the Economist Intelligence Unit [3] shows that well-defined methodologies in organizations give more confidence to project managers helping to deliver their projects with success. Faced with these facts, project management (PM) evolved from a set of recommended processes to a mandatory methodology, being crucial to the survival of the companies. However, it remains a challenge because there are still many projects that exceed budget, delay or fail to meet their objectives, as evidenced in several studies [4, 5]. According to the 
Gartner Group's worldwide survey, the percentage of unsuccessful projects (failed and con-tested) as of 2012 was 61\% [6]. However, a more recent study from PMI, in 2016, found that projects using proven project management practices were 2.5 times more successful [7]. Besner and Hobbs [8] study reveals significant differences in project management practices in different contexts and types of projects. The process of choosing the project management model to be developed in an organization is therefore very complex because many dimensions must be considered simultaneously, the effects of which may be contradictory [9]. According to Besner and Hobbs [8] these dimensions may vary depending on project size (in terms of budget and duration), project typology, degree of complexity, project similarity, and degree of project innovation. However, despite these variations in specific practices, Besner and Hobbs [10] confirm the position that project management is a generic discipline with a wide range of applicability.

The objective of this research was, through a study in a company in the automotive industry, to answer the following research question: How to improve project management practices in automotive industrialization projects? The goal was to determine which project management practices could be improved, and how, in order to improve the success of industrialization projects. In order to answer this central research question, the following specific objectives were defined: (1) Identification of the project management practices and difficulties at the company (As-Is Model); (2) Definition of an integrated project management process and identification of best project management practices to mitigate the difficulties and respond to the needs of the industrialization projects (To-Be Model).

This paper is organized as follows. In Section 2 the literature review that contributed to this research is presented. Section 3 presents the research methodology used. Section 4 presents the case study analysis and Section 5 the proposal of an integrated project management process to improve PM practices in the company. Finally, Section, 6 presents the conclusions.

\section{$2 \quad$ Literature Review}

This section presents a literature review on project management of industrialization projects and project management practices.

\subsection{Project Management of Industrialization Projects}

PM refers to the individual management of each project. It is the combination of people, techniques and systems needed to manage the resources necessary to successfully reach the end of the project [11]. It means doing what is necessary to complete the project within the established objectives. PMI [12] defines project management as being "the application of knowledge, skills, tools, and techniques to project activities to meet the project requirements".

The success of a project is usually measured at the end of the project. The project management success usually measured at project end, being a way to help the project to meet the budget, schedule and quality criteria. Each of these criteria is based on the 
comparison of the project objectives with what was actually achieved. For example, quality can be measured through the amount of rework or level of customer satisfaction.

Project management success is then linked to project success, and the two are inseparable [13]. However, success always varies from project to project taking into account the organizational context and the different stakeholders [14].

In industrialization projects specific context, the role of project management may not be as evident as it should be [15]. According to Perrotta, Araújo, Fernandes, Tereso and Faria [16] the process of industrialization involves the analysis/understanding of all product requirements, the development of prototypes to increase product maturity before moving to the design of the manufacturing line. Typically, clients (internal or external, depending on the origin of the request) participate in this process, receive some prototypes to make their own evaluation and then provide feedback to the industrializing company. This feedback can cause changes in the product, resulting in new requirements to be met by the product. New prototypes are then built and the process is repeated until all customer requirements are considered, allowing the production line development process to be started. Throughout the process of industrialization, the quality of the product must always be evaluated.

\subsection{Project Management Practices}

There are several studies about project management practices, including tools and techniques, which can help project manager professionals, in different contexts.

According to a study by White and Fortune [17], the most used tools in project management were: "off the shelf" software (77\%); Gantt charts (64\%); and cost-benefit analysis (37\%). This study is in line with a more recent survey by Besner and Hobbs [18], which was based on a questionnaire to 753 experienced project management participants. The results were a ranking of 70 techniques and tools by their degree of use. However, this study could not be applied directly to our study without first analyzing the context of the organization. A more recent study by Fernandes, Ward, and Araújo [19] also aimed to identify the most useful project management practices and the results present some similarities with the Besner and Hobbs study.

Perrotta, Fernandes, Araújo, Tereso and Faria [15] carried out a study, on the automotive industry, where the best practices for industrialization projects were identified. A survey was carried out with 17 industrialization project managers. Project planning is the practice at the top of the list, due to the importance of respecting the customer's deadlines, being a guide to develop the industrialization schedule and milestones. Second is lessons learned. According to the authors, knowledge gained through the development of new products can be useful for future projects, either in relation to new projects using similar technology or projects of the same client with specific needs. Third is ECR (Engineering Change Request). Due to the fast-paced environment and the innovative development of new manufacturing lines, it is very common to have processrelated changes and, as such, ECR must be completed to formalize, approve and record these changes [15]. 
A study from Tereso, Ribeiro, Fernandes, Loureiro and Ferreira [20] allowed to evaluate the 20 tools and practices most used for each group of project management processes in private companies. The top 20 cover the overall project management life cycle from initiation to project closing, but particular relevance is given to tools and techniques from planning, and curiously, to tools and techniques from closing.

\section{$3 \quad$ Research Methodology}

The methodology adopted presupposes a deductive approach that begins with the literature review to identify theories and studies, and then to apply it to practice. An analysis of the company's processes and procedures, regarding project management practices, was also made, in order to identify the main problems and difficulties. Subsequently, in order to answer the research question, semi-structured interviews were applied to the four project managers and the functional process manager of the organization under study. These interviews aimed to understand how the projects were managed and collect ideas to improve the process. After analyzing the data from these interviews, a 2hour focus group was conducted for a preliminary validation of the integrated project management process proposed by the researchers. It was an unstructured focus group, allowing the presentation of the integrated process and providing openness for improvement suggestions. The methodology used, inspired in Perrotta, Araújo, Fernandes, Tereso and Faria [16], allowed to identify and decompose the existent project management practices, defining the As-Is model. Then this model was used as a starting point for the development of the To-Be model.

\section{Case Study Analysis}

The industrialization in the company under study begins with the study of the production process, still during the development of the product, extending through the approval phase. This includes the validation of processes and tools to be implemented for the pre-series and series production, using tests that are articulated and updated simultaneously with the evolutions of the product. Included in industrialization is the logistics part, which defines the packaging and transportation of the product.

The process development life cycle is divided into the following phases: (1) Study: consists of the design of the injection tool, plating jig, control gauge, packaging and other tools needed for the process; (2) Construction: construction phase of the injection tool and all the tools necessary to obtain the final product, according to customer's requirements (plating jig, control gauge, packaging and others); (3) Testing and validation of processes and tools: preparation phase of injection tool tests, tests to the plating jig and general test with all the tools necessary for the product. After this process and closed tools, the final validation is carried out through the production of initial samples. With the nomination of the project, the client provides the last 2D plan and 3D of the part ordered, in order to be analyzed in detail and thus to define the necessary tools. The industrialization projects aim to develop tools that allow the subsequent production in series of a chrome part that meets the requirements of the customer. 
With the approval of the tools study, it is possible to proceed to the construction phase and then to the tests, in order to validate all the outputs. Upon completion of the project, the company begin the serial production of the parts.

A common process of industrialization usually lasts 24 months, however there are factors that can affect the duration of this process, such as: (1) Complexity of the part; (2) Workload, especially of the tool maker; (3) Any modifications to the part to ensure conformity in the assembly; (4) Deadlines agreed with the client.

With regard to the number of people directly involved in a project, this can range from eight to ten people, depending on the project complexity.

With regard to the project costs, these vary according to the typology of the product (size, complexity, client requirements). However, the tool that requires greater investment is the injection tool. It is not possible to quantify the average cost of this tool due to the fact that it varies with several factors, such as the number of cavities, their location and how to inject the part.

In the course of describing project management practice at the company, and in the interviews conducted, several difficulties were encountered that conditioned the development of a project. The main objective of these interviews was to survey all the difficulties and problems experienced, as well as to identify the practices and tools already used in the organization (Table 1).

\section{Proposal of PM Initiatives to Improve PM Practice}

During this section, a proposal for an integrated project process will be presented, thus describing the life cycles of the industrialization process development and project management. Proposals for improvements to the tools and techniques used in project management will also be presented. The proposed new practices / tools were based on literature review and interviews.

To validate the improvements, a focus group was performed. The stakeholders who participated have accepted the improvement proposals willingly, however there are proposals that involve a restructuring of the organization, so it is necessary to perform another focus group with the top management. Yet, due to time limitations and incompatibility of agendas, this was postponed to future work.

\subsection{Project Initiation}

This group of processes occurs after receipt of the client award, which can be done by sending the order of the tools, or with an official nomination letter. This phase includes the realization of the project charter, which corresponds to the definition of the project's characteristics, namely in terms of time, scope and cost. It contains a small description of the main deliverables and also appoints the project team that will follow up. Subsequent to the realization of the project charter, the contract revision meeting (Kick off) is made. Initiation is the stage at which the project is described in detail, so that its main purpose and objectives are understood. 
Regarding D1 difficulty (Table 1), it was possible to verify that there are projects awarded that are not always feasible in the first phase, and that there is a need to make changes to the product at the beginning of the project, which may contribute to eventual delays. The proposal presented by the researchers involve the creation of a new function in the company, namely the function of pre-project. The objective is to create viable alternatives to start the project phase. The person who would hold this position would be the link between the client, the budgeting department and the commercial department and would always intervene on the feasibility phase. This function would act in two main moments: (1) when the complexity of the project at the risk and technological level justifies it; (2) when the project is considered strategic (e.g. strategic customer, billing volume above normal, extension of the operation area).

Table 1. Difficulties found in the Project Management process (As-Is model).

\begin{tabular}{|c|c|c|c|}
\hline ID & $\begin{array}{l}\text { Project } \\
\text { phases }\end{array}$ & Difficulties (D) & $\begin{array}{l}\text { Causes according to the } \\
\text { interview analysis }\end{array}$ \\
\hline D1 & \multirow{3}{*}{ 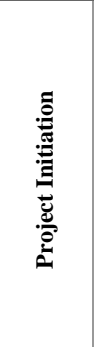 } & Existence of awarded non-feasible projects. & $\begin{array}{l}\text { Necessary change the part geometry in the middle } \\
\text { of the project due to the lack of a depth feasibility } \\
\text { analysis }\end{array}$ \\
\hline D2 & & $\begin{array}{l}\text { Limited autonomy of the project manager due to the } \\
\text { company's organizational structure. }\end{array}$ & $\begin{array}{l}\text { Currently the structure of the organization is func- } \\
\text { tional, where each team member of the project } \\
\text { has a hierarchical superior from a functional de- } \\
\text { partment. }\end{array}$ \\
\hline D3 & & $\begin{array}{l}\text { The company's management system does not include } \\
\text { two important standards, the development and innova- } \\
\text { tion management standard NP } 4457 \text {, and the project } \\
\text { management standard ISO } 21500 \text {. }\end{array}$ & $\begin{array}{l}\text { Implementation of these two norms by the im- } \\
\text { portance assigned to these standards in the man- } \\
\text { agement system of an organization. }\end{array}$ \\
\hline D4 & \multirow{2}{*}{$\begin{array}{l}\text { Initial } \\
\text { Planning }\end{array}$} & Responsibility of each project stakeholder is unclear. & Project responsibilities matrix does not existent. \\
\hline D5 & & Lack of detail of the work to be executed. & $\begin{array}{l}\text { There is no detail of the work to be done which } \\
\text { contributes to a PM non-standardized methodol- } \\
\text { ogy. }\end{array}$ \\
\hline D6 & \multirow{3}{*}{ 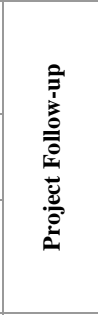 } & $\begin{array}{l}\text { Lack of some technical knowledge in meetings with } \\
\text { the client. }\end{array}$ & $\begin{array}{l}\text { The project manager is the main interlocutor with } \\
\text { the client, however he does not have the same } \\
\text { technical knowledge as for example the tool tech- } \\
\text { nician to respond assertively and immediately. }\end{array}$ \\
\hline D7 & & Loss of information during project follow-up. & $\begin{array}{l}\text { The existence of several projects simultaneously, } \\
\text { in different phases and with different teams, leads } \\
\text { to the loss of information. }\end{array}$ \\
\hline D8 & & $\begin{array}{l}\text { Difficulty in establishing contact with some of the ele- } \\
\text { ments of the team, which causes an increase of time in } \\
\text { the execution of the project activities, being the client } \\
\text { is more and more demanding. }\end{array}$ & $\begin{array}{l}\text { Production and logistics departments' physical } \\
\text { distant from the projects department. }\end{array}$ \\
\hline D9 & Closing I & Incomplete project closure documentation. & $\begin{array}{l}\text { Lack of a lessons learned template and project } \\
\text { closure report with little information. }\end{array}$ \\
\hline
\end{tabular}

After awarding the project, this person with this new function, would inform the project manager of the status so that the PM activities could begin.

Another proposal of the researchers in the project initiation phase would be to change the structure of the organization. The organization has a functional structure, where each project team member has a hierarchical superior. This type of structure tends to cause conflicts within the team. In order to avoid this situation, a structure by projects is proposed, thus giving full authority to the project manager regarding its team. He would only report to one person (project sponsor), reducing the communication channels and facilitating the communication. This would allow to overcome the difficulty 
D2. Still in this group of processes, more precisely in the integration management knowledge area, it was possible to identify that the Enterprise Management System does not include two important norms, both for the automotive industry and for project management, namely the NP 4457, standard for research, development and innovation management and the project management standard, ISO 21500 (D3). The researchers proposed that the company invest on the implementation of these two standards, as they will enhance the credibility and image of the organization, which will contribute to a potential increase in projects to be awarded. The acquisition of new customers and continuous improvement of their processes are other benefits that are expected with the implementation of these two standards. It is important to emphasize that the implementation of these standards naturally involves costs, however, the organization must take into account that the costs initially invested can bring a positive return in the medium/long term, increasing efficiency and productivity.

\subsection{Project Initial Planning}

After the project charter is formalized, the project initial planning will start, where all the subsidiary plans of the different areas of knowledge will be defined and integrated into the final project management plan.

In this phase, the researchers propose two new tools for project management: (1) the construction of a responsibility matrix that did not exist and will allow a clearer definition of the responsibility of each project stakeholder; (2) The construction of a WBS that will allow to have a more precise detail of the work to be done throughout the project.

\subsection{Project Follow-up}

The project follow-up phase concerns all work carried out in the development of the process, namely the study of the tools, the monitoring and control of the construction of the tools in the supplier and, finally, test and validation. This phase is responsible for monitoring, analyzing and recording the project progress, in order to meet the objectives that were defined. It also provides a clear view of the project performance.

During this process, corrective actions may be necessary, namely changes in the product, which may come from both the client and the organization that develops the project. To allow these changes it is important to add a re-planning process, which aims to reformulate the already existing planning, in order to avoid possible inaccuracies in time and cost estimates.

In the organization under study, it was possible to perceive some lack of technical knowledge in the meetings between the client and the project manager, both in the injection process and molds, and in the electroplating process (D6). To solve this situation, it was proposed the integration of a technical team member in the meetings where technical aspects are discussed. Meeting minutes are also proposed to avoid loss of information.

Increasingly, the client requires closer project monitoring, periodically requesting information and updating the project status. Thus, project team weekly meetings were 
proposed, whose objective is to improve the communication between the team members and to reduce the time of execution of the project activities, caused by the lack of response of these members. As an auxiliary tool for these meetings, the researchers created a template called Open Point List. The use of meeting minutes were also proposed.

\subsection{Project Closing}

Project closing phase includes the finalization of all project management activities. It integrates, among other things, customer acceptance, store of information and project handover to serial production, which is usually done after three months from the date of star of production.

Generally, at this stage, an analysis and validation of the lessons learned is performed, which in the studied organization did not happen. This is an important tool in this industry context, such as Perrotta, Fernandes, Araújo, Tereso and Faria [15] show in their study. The researchers proposed a template so that throughout the project all lessons learned are recorded. Additionally, the project closure report, which aims to formalize the closure of project management activities, was also improved.

At various points in the project it is possible to verify the interconnection between project management and the industrialization process development. In this way, and as shown in Figure 1, the integration of the processes of the both life cycles are presented.

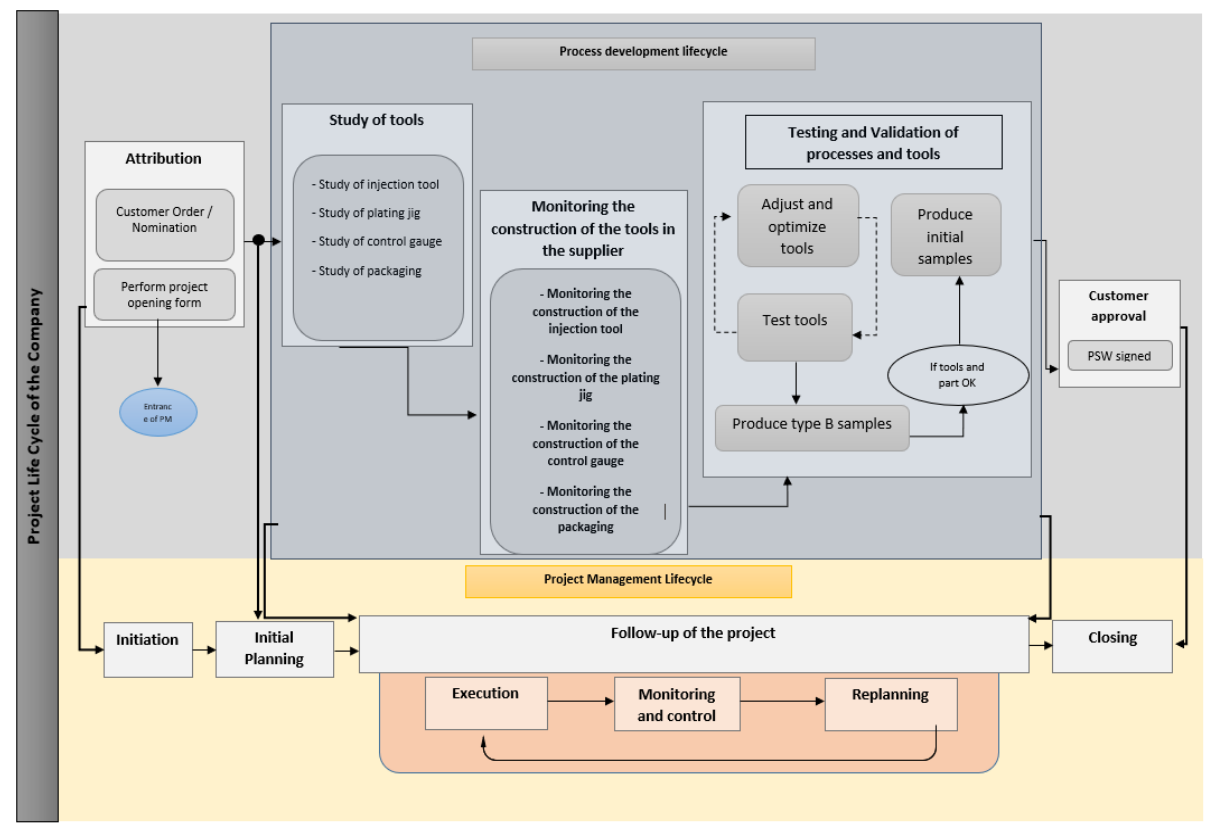

Fig. 1. Proposed integrated project management process between project management lifecycle and process development management lifecycle. 


\section{Conclusions}

This paper presents a study about improving project management in industrialization projects, developed in the context of the automotive industry. The work was developed in the form of a case study which may be of interest to other similar companies of the same area. However, as evidenced in the literature review, the organizational context must always be considered, so that the project management tools and techniques proposed are context-adjusted $[8,9,10]$.

It was possible to verify that the group of processes that the company needs to focus more on are from the project closing phase. According to the project managers, the reason why this group of processes is still a weak point in the company is because the awarded projects are always increasing, resulting in lack of time to focus on closure of ongoing projects, which contributes to neglecting this important project phase.

In industrialization projects, it is essential to document the lessons learned acquired throughout the project, as these can be useful for new projects that may use similar technology, or projects of the same client with specific needs [15].

It is important to emphasize the contribution of the studied organization in order to provide viable alternatives to ensure the success of the project management process. Although this study has a more applied aspect, it can be considered for possible future studies that want to develop an approach to the management of industrialization projects in similar organizations.

In summary, the researchers consider that the organization under study perceives the value of project management and has the necessary resources to implement the proposed improvements. Some tools and good practices have already been implemented, such as the project charter, the kick off meeting and the Gantt Chart. It is noteworthy that the company showed a strategic orientation for the future coincident with the proposed improvements. These proposals are understood as fundamental for the organization to create value, through the satisfaction of its customers and its employees.

Acknowledgements. This work has been supported by FCT - Fundação para a Ciência e Tecnologia within the Project Scope: UID/CEC/00319/2019.

\section{References}

1. Gobetto, M. (2014). From Industrial Strategies to Production Resources Management, Through the Industrialization Process and Supply Chain to Pursue Value Creation. Operations Management in Automotive Industries. Springer Netherlands.

2. Fernandes, G., Ward, S., Araújo, M. (2014). "Developing a Framework for Embedding Useful Project Management Improvement Initiatives in Organizations". Project Management Journal 45(4): 81-108.

3. EIU. (2010). Industrial manufacturing: Managing for success. Economist Intelligence Unit Limited, 1-18.

4. Pinto, R., \& Dominguez, C. (2012). Characterization of the Practice of Project Management in 30 Portuguese Metalworking Companies. Procedia Technology, 5, 83-92. 
5. The Standish Group. (2014). The Standish group: the chaos report. Retrieved from Project Smart.

6. Spalek, S. (2014). Success Factors in Project Management. Literature Review. Valencia, Spain: Education and Development Conference INTED2014.

7. Costa, I., Fernandes, G., \& Tereso, A. (2017). Integration of Project Management with NPD Process: A Metalworking Company Case Study. 23rd ICE/IEEE International Conference on Engineering, Technology and Innovation, Madeira Island, Portugal, 27-29 June 201.

8. Besner, C., \& Hobbs, B. (2013). Contextualized Project Management Practice: A Cluster Analysis of Practices and Best Practices. Project Management Journal, 17(1), 17-34.

9. Besner, C., \& Hobbs, B. (2012). An empirical identification of project management toolsets and a comparison among project types. Project Management Journal, 43, 24-46.

10. Besner, C., \& Hobbs, B. (2008). Project Management Practice, Generic or Contextual: A Reality Check. Project Management Journal, 39, 16-33.

11. Norat, S., Neto, E., Lucena, G., Martins, J., Castanheira, M., Eloy, R., ... Silva, W. (2011). Manual de Gestão de Projetos (1st ed.). Brasil.

12. PMI. (2017). A Guide to the Project Management Body of Knowledge (Sixth Edit). Project Management Institute.

13. Munns, A., \& Bjeirmi, B. (1996). The role of project management in achieving project success. International Journal of Project Management, 14(2), 81-87.

14. Milosevic, D., \& Patanakul, P. (2005). Project Standardized project management may increase development projects success. International Journal of Project Management, 23, 181-192.

15. Perrotta, D., Fernandes, G., Araújo, M., Tereso, A. \& Faria J. (2017). Usefulness of project management practices in industrialization projects - a case study. 23rd ICE/IEEE International Technology Management Conference, (27-29 June 2017).

16. Perrotta, D., Araújo, M., Fernandes, G., Tereso, A., \& Faria, J. (2017). Towards the development of a methodology for managing industrialization projects. Procedia Computer Science, 121, 874-882.

17. White, D., \& Fortune, J. (2002). Current practice in project management - an empirical study. International Journal of Project Management, 20(1), 1-11.

18. Besner, C., \& Hobbs, B. (2006). The perceived value and potential contribution of project management practices to project success. Project Management Journal, 37, 37-48.

19. Fernandes, G., Ward, S., Araújo, M. (2013). "Identifying useful project management practices: A mixed methodology approach." International Journal of Information Sys-tems and Project Management 1(4): 5-21.

20. Tereso, A., Ribeiro, P., Fernandes, G., Loureiro, I., \& Ferreira, M. (2018). Project Management Practices in Private Organizations. Project Management Journal, Vol. 50(1):1-17. 